\title{
PRESIDENTIAL ADDRESS: How to Improve Poverty Measurement in the United States
}

\begin{abstract}
This paper discusses the reasons why the current official U.S. poverty measure is outdated and nonresponsive to many anti-poverty initiatives. A variety of efforts to update and improve the statistic have failed, for political, technical, and institutional reasons. Meanwhile, the European Union is taking a very different approach to poverty measurement. The paper ends with four recommended steps that would allow the U.S. to improve its measurement of poverty and economic need."
\end{abstract}

\section{INTRODUCTION}

Because this paper has necessary space limitations, I will discuss only a restricted set of topics. Hence, I will ignore some important but more technical debates within the literature. I am going to focus almost entirely on so-called "headcount" measures of poverty, which indicate a certain share of people who fall below some definable point that indexes poverty or deprivation. The problems with this approach are well-known because it does not measure the depth of economic need. People who are poor could become poorer, with no change in a headcount measure of poverty. Headcount measures are widely used, however, because they are easily understood (important for a public and broadly used measure) and are often easier to implement than other more complex measures. Consistent with the use of the headcount, I will focus on a limited number of poverty measurement approaches that have been implemented in the United States or elsewhere. I mention a few alternative approaches below but spend little time discussing them.

The poverty measure in the United States is usually thought of as a measure of serious economic need or economic deprivation. Our historical definition of poverty focuses on income, the economic resources available to a family, rather than on outcome measures of consumption or well-being. "Living in poverty" suggests that a family has so little income that they are unable to purchase the things that we as a society think they need for a minimally decent life. In the United States, this typically means more than merely escaping starvation; it means being able to purchase the goods and services that are necessary to afford adequate and stable housing, find and hold a job (if physically able), participate as a citizen in the community, keep oneself and one's family reasonably healthy, and provide the things that one's children need to participate effectively in school.

An income-based measure of poverty requires agreement on at least four major definitional items. In this paper, I primarily address issues related to the first two of these. To begin, one needs to define a poverty threshold, the level of income or other resources below which a family is considered poor. Thresholds that are fixed over 
time in real terms (that is, they are entirely nonresponsive to economic growth or changes in living standards) are typically referred to as absolute. The official U.S. measure falls into this category. Thresholds that vary one-to-one with income growth (such as a threshold set at 50 percent of median income) are typically referred to as relative. The European Union and the OECD use such measures. It is, of course, possible to have a threshold that changes with income growth but has an elasticity of less than one.

The second necessary definition is a resource measure, defining which resources are counted for each family; the sum of these resources is then compared to the threshold to determine whether the persons in the family are poor. Discussions about the resource definition in the United States have included such issues as whether to include the value of in-kind programs in estimating income or whether to use after-tax rather than before-tax measures of income.

Third, it is important to agree about the level at which income is aggregated and over what time period. The current U.S. definition is based on the resources of all related and coresident family members over a calendar year. I will assume throughout this paper that we are interested in poverty rates based on annual income and that there is an agreed-upon definition of "family" whose annual income is being measured. In reality, there is substantial debate over whether poverty measures should be based on related individuals who live together (families), whether they should also include cohabiters, or whether they should include all coresidents (households). There is also debate over whether income should be measured for longer or shorter durations than one year.

Fourth, it is important to agree about how different family sizes are dealt with. One option is to develop a different threshold for each family size. An alternative option, used in both the United States and Europe, is to develop a threshold based on a modal family size and then calculate the threshold for other-sized families using an equivalence scale that determines the relative income level needed to keep families of different sizes at the same standard of living. Many papers have explored appropriate equivalence scales, and the scale proposed by Betson (1996) has been most used in alternative poverty calculations in recent years in the United States. ${ }^{1}$

Although there is widespread consensus that the current official measure of poverty in the United States is badly flawed, three decades of discussion and debate have not resulted in any changes to this statistic. To a casual observer, this may seem puzzling in a nation with a long tradition of regularly updated national statistics. The first several sections of this paper discuss current poverty measurement and various efforts at improvement, attempting to answer the question "Why has it been so difficult to improve the official measurement of poverty in the United States?"

While the United States has been embroiled in its own debate over poverty statistics, the European Union has moved in quite a different direction. The next part of this paper summarizes some alternative poverty measurement approaches that are being used elsewhere, with an eye to seeing what we in the United States can learn from these efforts. The final part of the paper makes a series of recommendations about how to move forward with improved measures of economic need, as well as broader measures of deprivation in other key social areas.

\section{THE OFFICIAL U.S. POVERTY DEFINITION DEVELOPED IN THE 1960s}

The official U.S. poverty definition was proposed when Mollie Orshansky, an employee of the Social Security Administration, was charged with putting together a measure of economic need to provide data useful to the War on Poverty initiatives.

${ }^{1}$ For a more extended discussion of all of these issues (and others), see Citro and Michael (1995) or Ruggles (1990); Haveman (2007) provides a recent overview of these issues. 
How to Improve Poverty Measurement in the United States / 235

Orshansky calculated a poverty threshold for a family of four in 1963, based on the definition: ${ }^{2}$

$$
\text { Poverty threshold }=3 \times \text { Subsistence food budget }
$$

The subsistence food budget for a family of four was the Economy Food Plan developed within the USDA in 1961 (based on the 1955 Household Food Consumption Survey) as the amount needed for "temporary or emergency use when funds are low." The average family of three or more spent one-third of their after-tax income on food in the 1955 Household Food Consumption Survey. ${ }^{3}$ If the average family spent one-third of its income on food, then three times the subsistence food budget provided an estimated poverty threshold.

An equivalence scale (based on differences in food budgets and relative expenditures among families of different sizes) was used to create multiple poverty thresholds for different types and sizes of families. Currently the official poverty thresholds vary by family size, number of children, and elderly/nonelderly householders. ${ }^{4}$

These 1963 thresholds have remained constant in real terms since that time. They are updated each year with the Consumer Price Index (CPI) ${ }^{5}$

The solid line in Figure 1 shows how these thresholds have fallen relative to median income, as economic growth has raised real incomes. In 1963, the poverty threshold for a family of four was set at just under 50 percent of median income. Over the years, this percent has slowly trended down, so by 2005 the threshold was at 28 percent. As we know, however, rising inequality has meant that real income growth among lower-income families has been slower than growth at the median.

The dotted line in Figure 1 shows the poverty threshold as a share of the 20th percentage point in the income distribution. This line is more cyclical (because incomes are more cyclical at this point in the distribution) but has shown no trend since the mid-1970s, meaning that there has been no real income growth at the 20th percentile of the U.S. income distribution for 30 years. The absence of real income growth at the bottom of the distribution has made the absolute U.S. poverty line more comparable across years, relative to the incomes of low-income families, than it might have been otherwise.

The resource measure in these poverty calculations was straightforwardly defined as all cash income. In 1963, this was a reasonable definition. Few very low-income families were paying federal taxes, given the tax brackets at the time. In-kind (noncash) programs like Food Stamps or housing assistance or Medicaid were either nonexistent or very small. Thus, cash income and disposable income were largely the same among low-income households.

The official poverty statistics are calculated each year using this threshold and resource definition, based on Current Population Survey data from the Annual Social

\footnotetext{
${ }^{2}$ For a more extended discussion of the analysis done by Orshansky, see Fisher (1997) or Weinberg (2006). This definition was later "backcast" to 1959, so we have official poverty statistics from 1959 onward.

${ }^{3}$ On the one hand, the food budget is designed for a low-income family. On the other hand, the multiplier is based on the food expenditure share of the average family. If the food expenditure share of a lowincome family were used, the multiplier would have been lower, because low-income families spend more of their income on food. A high food expenditure share is itself a sign of poverty, however. Orshansky assumed that low-income families should not spend more than the modal family as a food share.

${ }^{4}$ Earlier farm/nonfarm and female-headed/male-headed differences were dropped in 1981; there are currently 48 family types and sizes with a separate poverty threshold.

${ }^{5}$ From 1964 to 1969 , the thresholds were updated with a food budget price measure. Starting in the early 1980s, updates have been based on the CPI-U for urban consumers. There is clear evidence that the CPI-U overstated housing costs in the 1970s and early 1980s, so the actual threshold probably rose somewhat in real terms during this period. Adjustment for this would lower the poverty threshold (Bavier, 1999).
} 


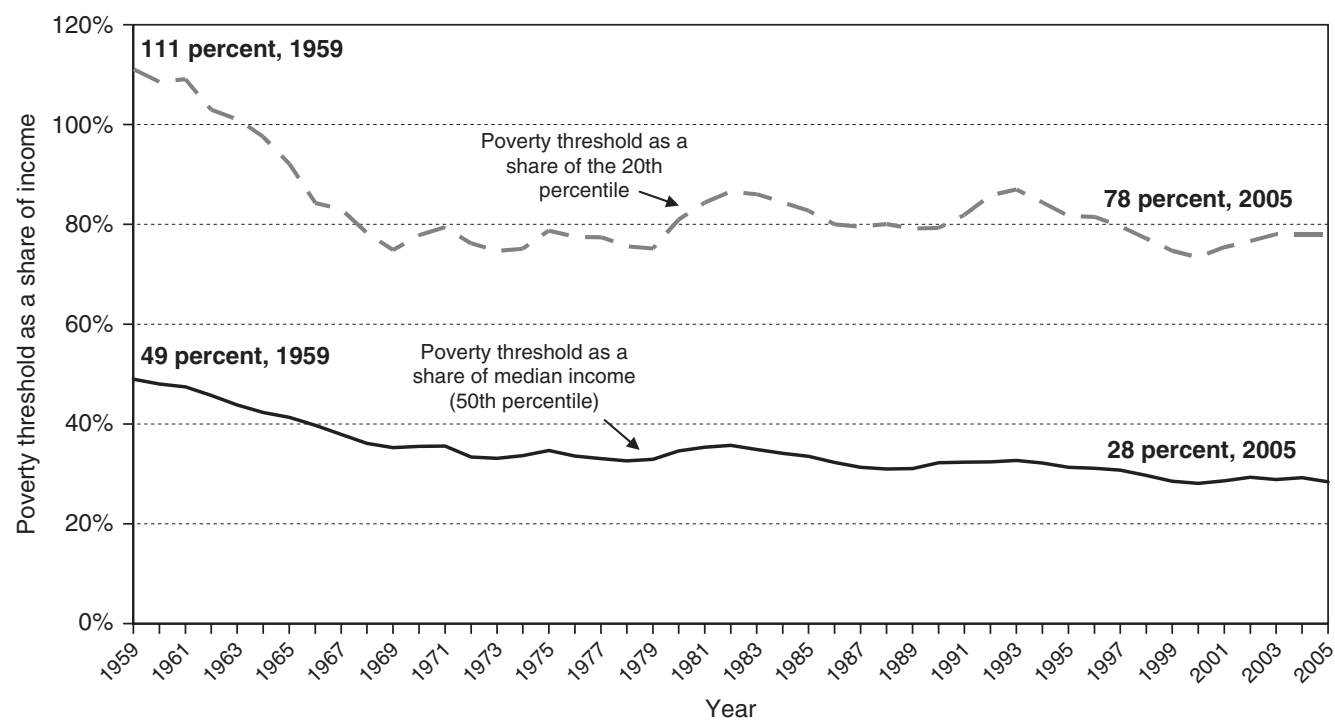

Source: U.S. Census Bureau. Poverty thresholds available from Historical Poverty Tables, http://www. census.gov/hhes/www/poverty/histpov/hstpov1.html. Income points available from Historical Income Tables-Families, http://www.census.gov/hhes/www/income/histinc/f08ar.html.

Note: Poverty threshold and median family income amounts are for families of four. The 20th percentile (the cut point at the top of the first quintile) is only available for all families.

Figure 1. Poverty threshold as a share of median income and as a share of the 20th percentile in the income distribution, 1959-2005.

and Economic Supplement (which asks about income in the previous year). Total family cash income is summed, and this sum is compared to the poverty threshold for a family of that size. If the family's cash income is below the threshold, all persons in the family are counted as poor. Figure 2 shows the official poverty rate based on this definition from 1959 through 2006. Although the poverty rate fell rapidly in the 1960s, it has largely fluctuated (with the macroeconomy) between 11 and 15 percent in the decades since. This graph demonstrates the much-discussed lack of progress against poverty (at least as measured by the official poverty definition) over the past 35 years.

This methodology was embedded as the official poverty calculation when the Bureau of the Budget (now the Office of Management and Budget [OMB]) issued a directive in 1969 stating that the Census Bureau should calculate and report this figure annually. ${ }^{6}$ I will return to this point below but note here that this is relatively unusual. Most government statistics are not defined by an OMB directive but are under the control and jurisdiction of one of the U.S. statistical agencies that has authority to implement improvements and updates over time. In contrast, any change in the official measurement of poverty requires a change in this directive. Because OMB sits within the Executive Office of the President, this means the White House needs to sign off on any change, a point that will be quite important later in this paper.

The criticisms of this methodology as a way to define a 2007 poverty rate are too numerous to list in any complete form here. ${ }^{7}$ It is not too strong a statement to say that, 43 years after they were developed, the poverty thresholds are nonsensical numbers. They are based on data from 1955 and do not reflect any information

${ }^{6}$ This was later replaced with Statistical Policy Directive 14 in 1978.

${ }^{7}$ For extensive critiques, see Ruggles (1990) and Citro and Michael (1995). 


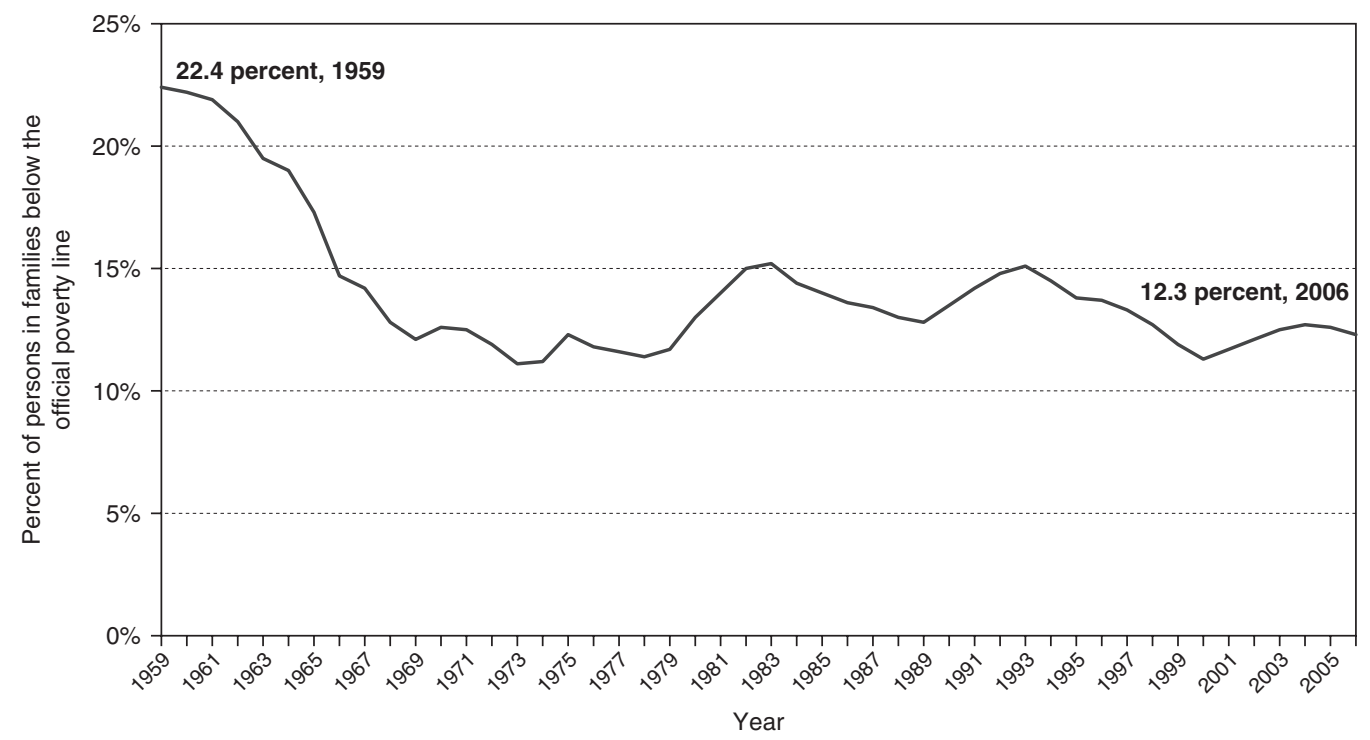

Source: U.S. Census Bureau, Historical Poverty Tables, http://www.census.gov/hhes/www/poverty/histpov/ hstpov1.html.

Figure 2. Official poverty rate, 1959-2006.

related to current expenditures or needs. If one sticks with a threshold based only on food costs, the current multiplier would be much higher because food has become relatively cheaper and food expenditures have declined precipitously as a share of overall expenditures. ${ }^{8}$ But basing the threshold numbers on a single commodity is almost surely not the correct way to calculate these thresholds because it leaves the numbers highly sensitive to the relative price of that commodity and insensitive to the price of any other likely expenditures, such as housing, among low-income families.

If the thresholds had been recalculated or rebenchmarked at any point since 1963, changes in methodology would surely have occurred. Without recalculation, if an appropriate price index is used, the poverty line today is at the same absolute level as in 1963. This raises the question of whether an absolute poverty line makes sense. As incomes grow or as behavioral expectations change, the things required to fully participate in society change. ${ }^{9}$ For this reason, many argue that at least partial adjustment for changing living standards should occur in the poverty thresholds.

The resource definition is also seriously flawed, as cash income alone is no longer an adequate description of the discretionary resources available to low-income families. There is broad agreement that the resource measure should reflect after-tax income. In the years after 1964, an increasing number of poor families began to pay federal income taxes as inflation eroded the tax brackets. Tax reforms in the mid1980 s solved this problem, giving the poor more disposable income, but these

${ }^{8}$ In 2005, 12.8 percent of pretax income was spent on food (U.S. Department of Labor, 2007, Table B); this would imply a multiplier of 7.8. This includes a rising share of discretionary spending on food eaten out that may not be appropriate to count fully for low-income families. A smaller food share would result in a higher multiplier. That said, updating by the CPI over time makes some adjustment for this because the share of food in the CPI has fallen. This is an indirect and less satisfying adjustment to the threshold than regular recalculation based on a broader set of necessities.

${ }^{9}$ One way to phrase this point is to note that the poverty thresholds have been unchanged for 43 years. If we "backcast" thresholds this far into the past, we would be using 1963 standards (and by implication the 2007 standards) to judge poverty in 1920. 
changes were not reflected in the poverty numbers. In more recent years, the tax system has been a source of additional funds for low-income working families because of the redistributive effects of refundable tax credits like the Earned Income Tax Credit (EITC).

Furthermore, the growth in in-kind benefits from public programs strongly suggests that in-kind benefits from near-cash programs, such as food stamps or housing assistance, should be imputed into family income. ${ }^{10}$ These programs have increased the resources available to low-income families. Finally, there are those who argue that discretionary income should exclude necessary work expenses as well as taxes. This includes transportation costs, but as more and more women go to work, it may also include child care expenses (at least, up to some cap).

Nevertheless, the problems with our current poverty calculation do not imply that the resulting poverty rates are entirely meaningless. Although this may not be the best way to define economic need, it provides some information on how many low-income families have limited cash income. The official poverty rates move with the economic cycle, and the measure is sensitive to changes in earnings and employment.

\section{WHY SHOULD WE CARE?}

Even though the work of Mollie Orshansky was well done, based on the data available in the early 1960s, the statistic that she suggested makes little sense in 2007 (and Orshansky herself argued strongly for updating the poverty calculation in later years). Let me underscore the major problems that this outdated statistic has created for policy analysis.

First, the statistic was remarkably impervious to most of the policies designed to improve life among low-income families that were implemented in the following decades. The 1970s saw rapid growth in food stamp and housing benefits, in-kind programs not measured in the resource definition. The last 30 years have also seen large expansions in publicly paid medical care, another in-kind benefit. The 1980s saw major reforms in the tax system that reduced tax burdens on low-income families; in the 1990s, the expansion of the EITC increased transfers from the tax system. Tax payments and tax refunds do not affect the poverty statistics.

A primary reason to want to measure economic need is to track the trends over time, looking at the effects of economic change as well as policy change. The public dollars that we put into antipoverty programs have grown enormously since the mid-1960s. But we have had an official poverty statistic that did not measure the impact of these changes on the economic resources of the poor. Although the poverty measure was designed to measure cash income, most public assistance has come in the form of noncash transfers. The exception to this is the expansion of Social Security and Supplemental Security Income to elderly low-income families. The sharp decline in poverty among the elderly, relative to other groups, largely reflects the fact that expanded public support for the elderly took the form of cash transfers.

As a result, Ronald Reagan was able to declare in 1988, "My friends, some years ago the federal government declared war on poverty and poverty won." ${ }^{11}$ Looking at Figure 2, this is a reasonable conclusion given stagnant poverty rates after the early 1970s. Although this was a period of rapid growth in public spending on the poor, its effects were invisible because we had no official statistic that reflected how this public spending improved the resources or the lives of low-income families. In a very fundamental way, our poverty statistics failed us and made it easy

\footnotetext{
10 There are debates about how to value the benefits of in-kind programs that are not a close substitute for cash (such as Medicaid benefits). See the discussion in Chapter 4 in Citro and Michael (1995).

${ }^{11}$ State of the Union address, January 25, 1988 (http://www.presidency.ucsb.edu/ws/print.php?pid=36035).
} 
to claim that public spending on the poor had little effect. Indeed, the primary statistical measure that we used to evaluate economic need could not possibly have measured the impact of these effects. For policy analysts, this should provide a jarring and memorable lesson in the importance of good statistics to the public debate and to public understanding of the impact of policy changes. Even in the 1990s, when a strong economy led to substantially reduced poverty rates, the reductions would have been even larger if expanded post-tax EITC subsidies were counted as income.

Furthermore, because the poverty definition became more and more irrelevant as a way to evaluate economic need, this opened up a statistical vacuum, making it possible for a wide variety of groups to make counterclaims about levels and trends in economic need. Although a common approach among those with a particular agenda is to calculate an "improved statistic," this has been particularly noticeable in the public debate over poverty. On the one hand, Robert Rector and colleagues (1999) have argued that poverty should be based on material hardship and claimed that in 1992 only 9.8 percent of single-parent families should be counted as disadvantaged. In contrast, Trudi Renwick and Barbara Bergmann (1993) developed a poverty threshold by building a "Basic Needs Budget" for low-income, single-parent families, emphasizing the amounts needed for adequate child care. In their estimates, poverty rates among single parents should be 47 percent.

\section{EFFORTS AT CHANGE}

Not surprisingly, problems with the poverty statistics have drawn attention from a wide spectrum of individuals. Quite a bit of work has gone into defining and calculating alternative definitions. I summarize here a few of the more recent and most visible public efforts.

One of the first thorough examinations of poverty measurement occurred in 1976, organized by the U.S. Department of Health, Education, and Welfare (1976). Although proposing a wide variety of possible improvements and changes in the official poverty measurement, this was the first of many reports that had little effect on the official measure but influenced internal work at the Census Bureau and led to the calculation of alternative (nonofficial) poverty numbers. The Census Bureau started to calculate experimental poverty rates using alternative resource measures in the early 1980 s, as in-kind income expanded within the low-income population. By the late 1980s, their experimental poverty rates used alternative resource definitions that took account of taxes, in-kind benefits, and limited housing imputations. ${ }^{12}$ Note that all of these alternatives focused on more inclusive resource definitions, without changes in the poverty thresholds.

In 1990, the Joint Economic Committee held hearings on poverty measurement; at the same time the Council of Economic Advisers, under President George Bush (the elder), proposed a statistical improvement initiative that included improvements in poverty. ${ }^{13}$ The discussion created by these initiatives led Congress to appropriate money for the National Academy of Sciences (NAS) to appoint a panel to make recommendations for improving the measurement of poverty. The resulting NAS report presented a template for poverty measurement changes (Citro \& Michael, 1995).

The NAS report recommended an approach that was conceptually consistent with Orshansky's efforts but that addressed many of the problems with the 1964 definition.

\footnotetext{
12 The first publication from the U.S. Census to value in-kind benefits in the resource measure and to provide alternative poverty counts was Smeeding (1982); alternative poverty measures using a broader measure of disposable income were first presented in the U.S. Department of Commerce (1990).

13 The JEC action was organized by Patricia Ruggles, then a JEC staffer who had recently written a book on poverty measurement (Ruggles, 1990) and was deeply interested in this issue.
} 
The committee recommended basing the threshold on expenditures on necessities (defined as expenditures on food, housing, and clothing), "plus a little more" (a multiplier of 1.10 to 1.15). A specified point below the median of the distribution of aggregate expenditures on necessities was chosen as the basis for this threshold. The committee recommended basing the resource definition on after-tax cash income, plus the imputed value of near-cash in-kind benefits, minus an adjustment for work expenses (transportation and child care expenses), minus an adjustment for out-of-pocket medical expenses. The committee also emphasized the importance of updating the threshold calculation regularly. This would lead to a quasi-relative poverty threshold. Expenditures on necessities increase when income grows, but more slowly than overall income growth. The committee suggested that the elasticity of expenditures on necessities to total income was between 0.65 and 0.80 (Citro \& Michael, 1995, p. 144). ${ }^{14}$

The committee addressed many other issues (equivalence scales, geographic price variation, etc.). For some issues, the NAS panel did not make a single recommendation but recommended a range of possibilities. This led to a variety of different poverty-line alternatives based on variations in the NAS recommendations. Both in the committee and in the years afterward, the most contentious issue was how to handle medical expenses. The committee recommended subtracting out-of-pocket medical expenses (up to a cap) from income but recommended against imputing the value of public health insurance into the income of recipients. ${ }^{15}$ In fact, one of the committee members dissented from the report, citing this issue among others. The recommendation to adjust the poverty thresholds for geographic price differences also ended up being quite controversial. Although the economic and statistical reasons for such adjustments are obvious, there are few federal programs with geographically adjusted benefits, and such adjustments in the poverty measure might well lead to demands that benefits be similarly adjusted, an argument that many policymakers would prefer to avoid. Furthermore, the data needed to calculate price indices by region are very limited, and official regional price indexes are not available.

In the years following the NAS report, an interagency committee chaired by OMB worked with the Census Bureau to operationalize the NAS recommendations using available data. The technical committee was (rightfully) quite wary about deciding on "the preferred alternative poverty line" and chose to calculate a number of variations on the NAS recommendations. The result was a report (U.S. Department of Commerce, 2001) that presented 24 different experimental poverty calculations, based on the NAS recommendations.

In 1998, there was also internal discussion within the Clinton White House about these NAS recommendations and the possibility of narrowing the number of alternative poverty lines that the Census Bureau might present and/or even selecting one of these alternatives to replace the official definition of poverty embedded in the OMB directive. ${ }^{16}$ Despite widespread agreement about the problems with the current poverty line, this discussion was tabled. ${ }^{17}$

There were at least three reasons for this. First, even if the new poverty rates were benchmarked to keep overall poverty constant in the initial year, the distribution of who was poor would change. For instance, the NAS alternatives resulted in fewer poor among those with large in-kind benefits, more working poor due to the

${ }^{14}$ For a more recent discussion of the pros and cons of the NAS measure, see Iceland (2005).

15 The argument is that few individuals, if given these dollars as cash, would actually buy health insurance with them, hence the insurance value should not be imputed as income. The committee recommended developing separate measures of "medical care risk" (see Recommendation 4.3, Citro and Michael, 1995). ${ }^{16}$ As a member of the Council of Economic Advisers, I pushed this agenda within the White House. The comments here reflect my own memories and experience.

17 This debate was later immortalized in an episode on the TV show The West Wing, in which everyone agreed the poverty measure needed revising and no one wanted to take on the potential political problems. 
subtraction of work expenses, and changes in the elderly poor due to equivalence scale changes that particularly affected one-person families and the subtraction of out-of-pocket medical expenses. This would almost surely evoke attention and criticism from at least some interest groups who were concerned with these changes.

In fact, both increases and decreases in the number of poor among a group could evoke concern. Increases in the poverty thresholds and in the poverty counts were problematic (what president wants to announce that poverty has gone up on his watch?). But decreases in the poverty counts were a problem too, appearing to minimize economic need among groups that used this as a way to garner political attention and to ensure access to social assistance programs within their population.

Second, a variety of public programs used poverty rates to allocate funding or used a multiple of the existing poverty threshold to determine family eligibility. (Rather than using the complex set of official thresholds, programs used a simplified version known as the Poverty Income Guidelines.) ${ }^{18}$ For instance, the Medicaid program in the mid-1990s mandated that pregnant women and children in families with incomes up to 133 percent of the federal poverty guidelines must be covered; states could choose to increase coverage to families up to 185 percent of the poverty guidelines. Other programs had similar provisions. The politics of dealing with program eligibility changes and formula fights were, at best, daunting. This issue could be dealt with through grandfathering clauses or, perhaps most obviously, by allowing programs to continue to use the old poverty definitions, making a change only at their own discretion. The background work on this issue had not been done, however, and this concern made politically minded staffers very nervous about changing poverty measurement.

Third, the strongest support for such a change came from a small group of statisticians and economists, not a primary constituency for any administration. The Republican Congress had its own agenda in the late 1990s and there was little support for this issue on the Hill. This only increased the likely political attacks any effort at change would generate. In the end, the costs of dealing with this issue overwhelmed any benefits from the White House perspective. Hence by the late 1990s, the primary effect of the NAS report was the regular calculation of a large number of experimental poverty lines by the Census Bureau, based on the NAS recommendations.

The issue of poverty measurement reemerged in the early 2000s inside the Bush (the younger) administration. Doug Besharov, a senior scholar at American Enterprise Institute (AEI), initiated the Project to Reconsider the Official Federal Poverty Measure, with two coconveners who were senior political appointees at the Department of Commerce and the Department of Health and Human Services (HHS). ${ }^{19}$ Besharov pulled together a group of senior people from the Census Bureau, the Bureau of Labor Statistics, OMB, and other agencies, along with a small group of researchers and policy analysts. This group met regularly for about a year and commissioned a number of papers. The conversations were open-ended, without any decisions or final report from the group.

Soon after these meetings, a decision was made by senior people inside Commerce and at the Census Bureau to stop featuring the NAS experimental measures and to publish a new set of alternative measures. Most notably, these changes abandoned the effort to update both the threshold definitions and the resource measure. Unlike the NAS report and what had appeared to be a broad academic consensus in the decade following the NAS report, the new experimental measures focused only

18 The Poverty Guidelines collapse the 48 poverty thresholds into 8 thresholds based only on family size, which provide an easy benchmark against which programs can compare income (income definitions often vary across programs) and calculate program eligibility.

19 Michael O'Grady was assistant secretary for Planning and Evaluation at HHS and Kathleen Cooper was the undersecretary for Economic Affairs at Commerce. 
on the resource side of the equation. They included four alternatives, which expanded the resource measures with different combinations of taxes, in-kind benefits, and the imputed value of home equity (U.S. Department of Commerce, 2005). Because all of these changes add additional resources into the resource definition, these experimental measures produced substantially lower overall poverty rates. Another set of alternatives was calculated that did not change the underlying threshold calculation but utilized a different CPI adjustment starting in 1978, which substantially lowered the thresholds by 2002 and hence also led to much lower poverty rates. ${ }^{20}$ Some of the staff within Census argued against dropping the NAS calculations entirely. The compromise solution was to continue to calculate and post the NAS experimental poverty rates online but to publish the new alternatives. As of the mid-2000s, this is where the calculation of alternative poverty lines stood with regard to Censuscalculated data.

Let me take stock of this history. Despite widespread agreement about some of the deficiencies of the current official poverty line, no substantial changes in that measure have occurred. Furthermore, although the overall thrust of the NAS recommendations was viewed as a credible alternative by many policy analysts and researchers, there was disagreement about some of the specific recommendations. As a result, agreement has not coalesced around one specific alternative calculation. Although the Census Bureau has been very interested in poverty measurement and has devoted substantial resources to new experimental and alternative measures, its efforts have largely resulted in a proliferation of alternative measures, without agreement on the comparative merits of the different measures.

Why are we stuck in this place? I think there are at least three primary reasons. First, and most important, is the odd historical accident that led the Executive Office of the President to be in charge of the official poverty measure. Primary responsibility for defining and updating virtually all other economic statistics lies within one of the statistical agencies. Updating and changing economic statistics occurs all the time within these agencies, even for statistics with much greater visibility, policy, and program value than the poverty rate. For instance, major changes in the ways in which questions were asked about employment created changes in employment and unemployment numbers in 1993. Debate about the appropriate benchmarking for the Consumer Price Index led to a series of quite substantial changes in how that statistic was calculated. The underlying analysis for these changes is overseen by the statistical agencies; although these agencies report to political appointees inside Executive Branch cabinet agencies, there is a long tradition of allowing them to do their job with minimal intervention.

Control over the measure of poverty, however, resides at OMB. Any changes to the current OMB directive will necessarily pass through key political decision makers within the White House. This means that they must take direct responsibility for any changes in official poverty measurement, as opposed to simply approving the recommendations of a statistical agency with some historical independence. Any White House (Republican or Democratic) is likely to see far more costs than gains from such changes. If we need an example of why economic statistics should be in the hands of statistical agencies, the long-term stalemate over poverty measurement provides an excellent one! At a minimum, this suggests that future poverty calculations need to be located in one of the statistical agencies, which should be given explicit authority to make decisions over time regarding this measure.

Second, changes in poverty have become harder the longer the statistic has gone without changes, in part because the current poverty measure is used by a large number of

${ }^{20}$ This last change is particularly unusual. Rather than updating with a better technique into the future, it makes very substantial changes in the historical series from 1978 on, which is usually not done with statistical updates. For a critique of this and other recent changes, see Bernstein and Sherman (2006). 
programs. According to a recent Congressional Research Service estimate (Gabe, 2007), 82 federal programs use the official poverty rate (typically as a basis for allocating funds) or the Poverty Guidelines (typically as one element in their eligibility determinations). The result is that any changes in the definition of thresholds or the measurement of poverty raise the possibility of changes in funding allocation or program eligibility. The longer the statistic is unchanged, the bigger the potential changes when updating occurs. This considerably raises the resistance to changes in poverty measurement.

It is worth noting that other statistics are also used in program outcomes. The CPI, for instance, is used to make annual changes to benefits in many public and private sector programs. Revised CPI numbers are implemented once available, but historical adjustments are not made retroactively. Similarly, when new census data are available every 10 years, a variety of programs are affected, from the number of congressional seats in a state, to eligibility for certain federal matching dollars. In short, we have quite a bit of experience in adjusting to updated data and statistics, and there is nothing inherently harder about adjusting to updates in poverty measurement.

Because the existing poverty thresholds and the resulting poverty rates can continue to be calculated, programs can stay with their current rules, pegged to the OMB-defined poverty measure. At a future point, programs could individually decide whether there are reasons to change their rules to coincide with a different poverty measure. A grandfather clause can assure ongoing eligibility for those on the program who entered it under older eligibility limits. In reality, few programs are going to want to make substantial changes in eligibility thresholds. Hence, even if a program decides to use a multiple of the new poverty thresholds, it is likely to seek a cutoff point very close to the number currently in use.

Third, a key difficulty in seeking agreement about a new alternative poverty measure is that "poverty" is an inherently vague concept, and developing a poverty measure requires a number of relatively arbitrary assumptions. Although all statistics require some value judgment about how they are constructed, the very concept of "economic need" is vague. There is no "right" way to develop poverty thresholds or resource measures. Substantial disagreements exist about the nature of need among low-income American families, which have echoed through our debates over welfare reform for many decades. At the end of the day, the statistician must make a call that balances good statistical measurement with astute political and social judgment about acceptable public definitions of poverty. The decisions are not always obvious, however, as indicated by the ongoing debates about whether and how to make geographical adjustments, child care expense adjustments, and medical expense adjustments to the measure of poverty.

The NAS committee discussed this explicitly in developing their measure for the poverty thresholds, trying for a measure that would be acceptable to a broad population (hence, expenditures on necessities plus a little more). Of course, given the role for judgment in this decision, those who engage in poverty measurement can often be quite influenced by their sense of where they want to end up. It is perhaps not surprising that persons who believe poverty is an overrated problem in the United States have argued for imputing the value of in-kind benefits in resources without changing the thresholds (which would unambiguously lower poverty counts). Meanwhile, those who believe that poverty is a serious problem are more likely to argue for methodologies that lead to substantially higher thresholds (and hence higher poverty counts).

Creating an improved poverty measure that is based on a reasonable threshold and income definition in 2007 requires good statistical analysis. Whether this raises or lowers the poverty rate is less important than whether this produces a measure that is sensitive to the policy and economic changes that impact economic need over time. Ultimately, as I argue below, economic disadvantage is a complex concept, 
and multiple measures, each measuring different aspects of economic need, might be preferable to relying on one single measure.

\section{WHAT CAN WE LEARN FROM OTHER COUNTRIES?}

Although the United States has been engaged in a long, technical, and largely stalemated argument about how to appropriately revise the official poverty line, our partners across the Atlantic have made substantial strides in developing measures of economic need that are quite different from those used in the United States. Few people in the United States realize the extent to which the European Union has put substantial resources into improving E.U. measures of economic hardship. A very interesting set of measures is currently being calculated and published throughout Europe. Raising our heads above our own colloquial arguments and looking overseas should lead us to think much more broadly about appropriate poverty measurement strategies.

The European Union (and the OECD as well) started from a very different place from the United States, with an initial focus on relative poverty measures. The standard calculation has been to take a percentage of median income as the poverty threshold, typically with cash income as the resource measure. ${ }^{21}$ The European Union currently uses 60 percent of median income as its standard calculation, which they refer to not as a poverty rate, but as an "at risk of poverty rate." 22 As noted below, this is only one of a number of primary indicators of social and economic disadvantage; however, let me focus for a moment on this particular measure.

The focus on relative poverty lines reflects a European-based conversation that emphasizes capabilities rather than absolute disadvantage. The well-being of a person relates to their functioning, that is, what they manage to do or be (Sen, 1992). Such a definition of well-being is necessarily made in the context of the current standard of living, which defines expectations about what constitutes well-being and social and economic participation. This approach has led European policy analysts down a very different track so that, although relative poverty measures have received very little serious attention in the U.S. policy community, U.S.-style absolute measures have received very little serious attention in the European policy community.

Relative poverty lines do have a major advantage in that they are easy to calculate when based on median incomes, and they avoid the extended U.S. debate about how to calculate an appropriate threshold. One disadvantage of a relative measure based on share of median income is that it is harder to make progress against poverty because the poverty threshold rises as incomes rise. For instance, Ireland has experienced very rapid income growth in the last decade, with some widening in their income distribution. As a result, Irish poverty numbers, based on relative measures, show increases in poverty even though incomes throughout the Irish income distribution have risen strongly. Absolute Irish poverty measures show sharp declines in poverty (Nolan, Munzi, \& Smeeding, 2005). When incomes fall, a relative threshold would fall as well and could lead to a perverse effect of lower poverty rates in a recession. The relative poverty measure essentially provides a measure of the spread in the income distribution below the median rather than a measure of absolute need or disadvantage.

Figure 3 uses calculations from Notten and de Neubourg (2007) to look at poverty rates in the United States and some of the larger Western European countries, based on two definitions. ${ }^{23}$ The solid bars show poverty rates, calculated as the percent of

${ }^{21}$ In-kind benefits are less common in Europe, where most transfers are cash. Furthermore, calculating consistent tax payments across multiple European countries can be daunting.

22 The OECD often uses 70 percent of median income.

${ }^{23}$ Smeeding (2006) provides similar numbers. 


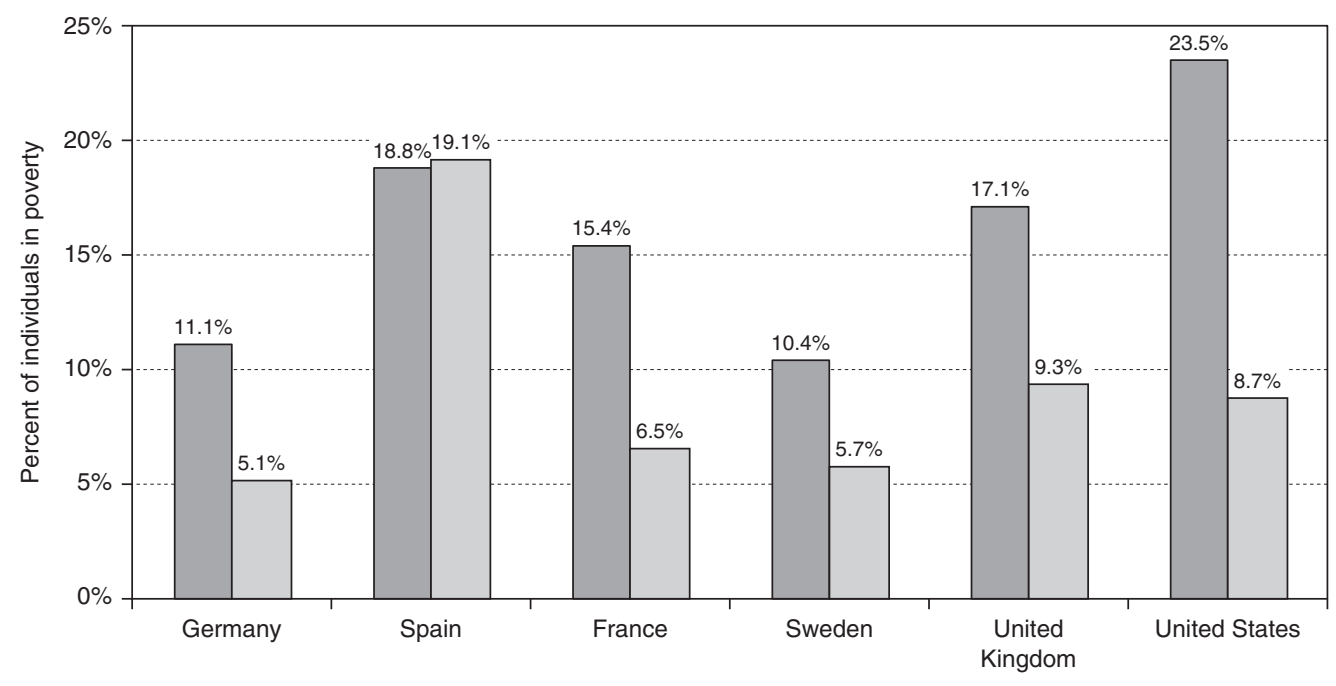

Relative $(60 \%$ of median income)

Absolute (U.S. poverty line)

Source: Data from Notten and de Neubourg (2007), Appendix Table A4.

Note: Relative poverty is measured by Notten and de Neubourg using the EU measure, with thresholds set at 60 percent of the national median adult equivalent income. Absolute poverty thresholds are set equal to the 1993 poverty thresholds for the United States, adjusted with the 1993 country-specfic Purchasing Power Parity (PPP) rates provided by the OECD. Thresholds are updated to 2000 using the Consumer Price Index (CPI) for each country. Income is measured after tax.

Figure 3. Relative and absolute poverty incidence across countries, 2000.

persons with family incomes below 60 percent of median income, the E.U. definition. The striped bars show the percent of persons below the current U.S. poverty threshold definition. These calculations use after-tax income as their resource measure (a different definition than used in the official U.S. poverty measure); the U.S. poverty threshold is translated into a euro level in each country, using national purchasing power comparison data. ${ }^{24}$

As Figure 3 indicates, based on relative poverty calculations, the United States has one of the highest poverty rates among industrialized countries, at 23.5 percent. This reflects the much more widely spread income distribution in the United States. Of course, median incomes in the United States are also relatively high. An absolute poverty measure, which would cut at the equivalent dollar or euro level in each country, shows much-reduced poverty numbers in all countries except Spain. Poverty is still relatively higher in the United States, but the differences are not great. It should be clear that the U.S. poverty threshold sits at a much lower point in the income distribution for all of these countries (except Spain) and hence may be closer to a definition of serious economic need rather than the "at risk of poverty" definition used in Europe.

It is perhaps not surprising that a country with more emphasis on economic freedom and with a wider distribution of economic outcomes would find an absolute poverty line more attractive. My guess is that completely relative poverty lines will continue to be unpalatable in U.S. poverty discussions. On the other hand, social standards do change over time. Items that were once luxuries become necessities for being part of mainstream society. For instance, having a phone is almost a

\footnotetext{
${ }^{24}$ These calculations are based on the Panel Study of Income Dynamics data in the United States rather than on the Current Population Survey on which official U.S. poverty statistics are based. By itself, this results in slightly lower U.S. poverty rates, because the PSID measures more income among lower-income families.
} 
necessity if one is a parent or employed. Few people would find a poverty line acceptable if it were based on the assumption that poor individuals maintain outdoor toilets, do their wash by hand, use candles rather than electric lights, and never travel in a car. Yet, these assumptions would seem quite reasonable for a poverty line developed 150 years ago.

Hence, even if a one-to-one correspondence between growth in the poverty threshold and in income levels does not seem reasonable to many Americans, something other than a completely absolute line may be attractive. This was certainly the reasoning within the NAS panel, and I find little reason to disagree more than 10 years later. Poverty thresholds should be updated over time, even if at a much slower rate than the growth in median incomes.

Although the relative-versus-absolute comparisons are important and interesting, it is not the calculation of widespread relative poverty measures within Europe that is most interesting to a U.S. observer. Most interesting is the extent to which European countries have successfully moved toward implementing a wide variety of measures of disadvantage, including measures of direct material deprivation. ${ }^{25}$

Multiple measures of disadvantage were recommended by a special committee of experts appointed within the European Union and headed by Tony Atkinson, an eminent British academic who has written extensively about poverty measurement. The resulting report (Atkinson, Cantilon, Marlier, \& Nolan, 2002) recommends that the European Union measure the capacity to achieve social inclusion along a variety of dimensions. Three levels of indicators are suggested, with level 1 indicators providing the most important country-specific measures reported consistently across the European Union; level 2 indicators provide supplemental country-specific measures that all countries must report; level 3 indicators are measures that individual countries might want to calculate and report. To ensure consistent and credible data, the European Union has also expanded its cross-country data collection efforts.

Table 1 provides the current list of level 1 and level 2 indicators of social inclusion. ${ }^{26}$ A quick look at Table 1 makes it clear that the European Union is measuring a much wider range of issues related to economic and social deprivation than any single poverty measure can capture. Particularly interesting are their measures of poverty persistence and their measures of education and health outcomes. These social exclusion measures are designed to provide benchmarks on much more than just the extent of low incomes.

The United Kingdom has been particularly active in developing its own indicators of material deprivation. The most current report (Department for Work and Pensions, 2007) tracks 23 indicators for young people, 18 indicators for people of working age, 10 indicators for people in later life, and 7 community-level indicators. The annual report discusses each indicator and explains how the data are trending relative to previous reports. The result is an amazingly rich picture of well-being among different population groups in the United Kingdom.

There are a variety of reasons to find a multiple-indicators approach attractive. Multiple indicators allow one to measure economic need in a variety of ways. It is a heroic assumption to believe that a single poverty measure can reflect most aspects of economic need. Indeed, part of the argument over the U.S. measure has occurred because different people want it to reflect different things. This has been most obvious in the debate over how to account for health care coverage in the NAS measure. Having information on a family's access to health insurance (this can be

\footnotetext{
${ }^{25}$ I use "material deprivation" as a term referring to a person's or family's access to some specific type of commodity. This could be housing, health care, education, etc. The "threshold" in this case is the line above or below which one believes access to this commodity is seriously impaired. The resource definition is the level of access available to any particular person or family.

${ }^{26}$ The European Union is in the process of revising this list; for more information, see European Commission (2006).
} 
Table 1. Social exclusion indicators collected for all EU countries, 2005.

\section{A. Level One Indicators}

1. At-risk-of-poverty rate

2. At-risk-of-poverty threshold

3. Income quintile ratio

4. Persistent at-risk-of-poverty rate

5. Relative median poverty risk

6. Regional cohesion

7. Long-term unemployment rate

8. Population living in jobless households

9. Early school leavers not in education or training

10. Low reading literacy performance of pupils

11. Life expectancy

12. Self-described health status by income level

\section{B. Level Two Indicators}

13. Dispersion around the at-risk-of-poverty threshold

14. At-risk-of-poverty rate anchored at a moment in time

15. At-risk-of-poverty rate before social cash transfers

16. Gini coefficient

17. Alternative persistent at-risk-of-poverty rate

18. Working poor

19. Long-term unemployment share

20. Very long-term unemployment rate

21. Persons with low educational attainment
Share of persons living in households with an income below 60 percent of national median income

60 percent of national median income

Ratio of the income of the 80th percentile over the income of the 20th percentile in the income distribution

Share of persons below the at-risk-of-poverty threshold in the current year and two of the last three years

Difference between the median income of persons below the at-risk-of-poverty threshold and the threshold itself

Coefficient of variation of employment rates within subnational regions

Proportion of labor force who have been unemployed 12 months or longer

Proportion of persons living in

households in which no one works for pay

Share of persons 18 to 24 with only

lower secondary education who have not been in education or training for the past four weeks Share of 15-year-old students who are at level 1 or below of the PISA combined reading literacy scale

Number of years a person aged 0,1 , and 60 may be expected to live

Proportion of population aged 16 and older who classify themselves as in a bad or very bad state of health

Share of persons with an income below 40 percent, 50 percent, and 70 percent of the national median income

Share of persons with an income below the at-risk-of-poverty threshold, using the threshold from three years previous updated for inflation

Current at-risk-of-poverty rate when all government and social cash transfers are excluded from income

Summary measure of income inequality Share of persons with an income below 50 percent of median income in the current year and in two of the last three years Employed persons who are at risk of poverty Total long-term unemployed population as a proportion of the total unemployed population

Proportion of total labor force who have been unemployed for 24 months or longer Share of the adult population whose highest level of education or training is at the lower secondary level 
either a zero/one measure of coverage or a more complex measure of adequacy of coverage) is an important indicator of the economic risks the family might be facing. Looking at measures of both health care coverage and income poverty tells us more than looking at either measure alone. Looking at the cross-tabulations between the two measures is particularly revealing, telling us something about how broadly lack of health insurance extends outside of the low-income population.

Furthermore, multiple measures of economic deprivation may avoid some of the intense debates about measurement that are inevitable when everything comes down to a single number. As noted above, "economic need" is an inherently vague notion. Providing multiple measures of need, including measures that indicate how many people actually have access to certain types of commodities or services, allows for a much more nuanced discussion of economic need and how it might be changing. ${ }^{27} \mathrm{~A}$ measure of resource poverty-such as the NAS poverty measure proposesis a very useful construct that we need to benchmark progress against economic need. But it is surely not the only valuable measure of need. The NAS report itself recommended that multiple measures of need be developed. ${ }^{28}$

Measures of material deprivation alone are not an adequate measure of economic need. Such measures ignore how material wants are satisfied. For instance, a family may be extremely poor in the short run but compensate by selling their house or borrowing heavily. A material deprivation index may not count this family in need. Furthermore, such measures rarely account for the quality of goods and services received. A rental unit that is infested with rats may appear adequate if measured by size or by rent burden (the share of rent being paid from family income). These material deprivation measures provide additional and useful information to income-based need calculations; they are not a substitute.

Different U.S. agencies already provide a range of material deprivation statistics, including food security (U.S. Department of Agriculture), housing quality (U.S. Department of Housing and Urban Development), child well-being (HHS), health insurance coverage (HHS), and educational achievement (U.S. Department of Education). Unlike the European Union, however, there is no effort to identify a key set of indicators, nor are these statistics regularly cross-tabulated with each other or with income poverty.

\section{OTHER APPROACHES TO SETTING POVERTY THRESHOLDS}

In addition to an expenditure-based threshold (such as the official poverty line and the NAS alternatives recommended) or a percent-of-median-income threshold (such as is used in European nations), there are a variety of other proposals for determining poverty thresholds. I mention these briefly, both for completeness and because they indicate something about why the opinions on appropriate poverty measurement are so divergent in the United States.

One much-discussed way of setting a poverty threshold is to build it from the bottom up, based on specific items and their prices. This is often referred to as a "poverty budget" approach, because it bases the poverty threshold on a particular market basket of goods. Recent examples of this include Renwick and Bergman (1993); Bernstein, Brocht, and Spade-Aguilar (2000); and the Family Economics Self-Sufficiency Project, organized by Diana Pearce. ${ }^{29}$

\footnotetext{
${ }^{27}$ A variety of researchers have argued that measures of material deprivation are superior to income poverty measures. For instance, see Meyer and Sullivan (2003) or Jencks, Mayer, and Swingle (2004).

${ }^{28}$ Recommendation 4.3 calls for separate measures of "medical care risk"; Recommendation 6.1 calls for measures of poverty persistence; Recommendation 6.4 calls for a measure of pretransfer and pretax poverty (Citro \& Michael, 1995).

${ }_{29}$ Pearce's budget calculations are described on the Web at http://www.sixstrategies.org/sixstrategies/ selfsufficiencystandard.cfm. A variety of specific publications implementing a self-sufficiency budget in a particular state are available on the Web site www.sixstrategies.org, which provides more information.
} 
A major drawback to poverty budgets is that they require even more assumptions and are open to many more arguments. By delineating what one expects poor families to buy and/or how much they should spend on specific types of commodities, one imposes a set of "rules" about consumption that may or may not be palatable. Differences across ethnic groups or regions, for instance, might lead to quite different market baskets. For this reason, market-basket approaches are hard to implement in a cross-country context and may be difficult in a large heterogeneous country like the United States.

A different approach is to set a poverty threshold based upon self-reported information, the so-called "subjective poverty threshold" approach. For instance, the Gallup polls for many years asked people how much a family of four would need to "get along in your local community." Other researchers have done extensive work with these sorts of subjective questions (Hagenaars, 1986; Vaughn, 1993), asking people to provide their own sense of "economic need."

Figure 4 provides a sense of how subjective responses correlate with the official poverty line and with relative poverty lines, using the Gallup poll responses. Gallup asked this question regularly through 1993 and did not ask it again until 2007, so we lack annual information over the past 14 years. The diamond-shaped blocks show the mean among all respondents during the years in which this information is readily available. The rectangular blocks show the median response among all respondents in 1967, 1987, and 2007. ${ }^{30}$ Figure 4 also plots the poverty threshold if set at 50 percent of median income (the dashed line) and at 50 percent of mean income for a family of four (the dotted line), as well as the official poverty thresholds for a family of four (the solid line).

Interestingly, Figure 4 suggests that the relative poverty line, based on 50 percent of median income, and the subjective poverty line followed each other very closely through the late 1980s. This suggests that people think about economic need in relative rather than absolute terms, and it is one reason why some people argue for relative poverty lines. The divergence after the late 1980s is interesting. With growing inequality, it appears that the subjective measure is better benchmarked to a relative measure based on mean income (which of course rises faster when inequality is rising) rather than median income.

In Figure 4, it is worth noting that in the early 1960s the official poverty line, the 50 percent of median or mean poverty lines, and the subjective poverty line were all almost identical. In the 45 years since, relative poverty lines and the subjective poverty line have increased substantially faster than the absolute poverty line. There are widely varying views about this. Some will argue that this demonstrates the problems with an absolute poverty line and indicates that our measures of economic need should be far higher than the official poverty line indicates. Others will argue that this shows why relative and subjective poverty are not useful concepts, because the absolute poverty line shows how much progress we have made over the past 40 years, relative to a fixed income threshold.

\section{HOW DO WE BREAK OUT OF THE CURRENT STALEMATE ON U.S. POVERTY MEASUREMENT?}

If we are serious about improving the measurement of poverty in the United States, I would recommend taking four actions. None of these are quickly done but will require the active intervention of Congress, which means finding members who will help make these changes happen. Some support for these changes within the relevant cabinet agencies would be helpful as well, as would support within the

${ }^{30}$ I have only the published median response for 2007 and was not able to obtain the mean response. Figure 4 shows the comparative median responses in earlier years as a comparison. 


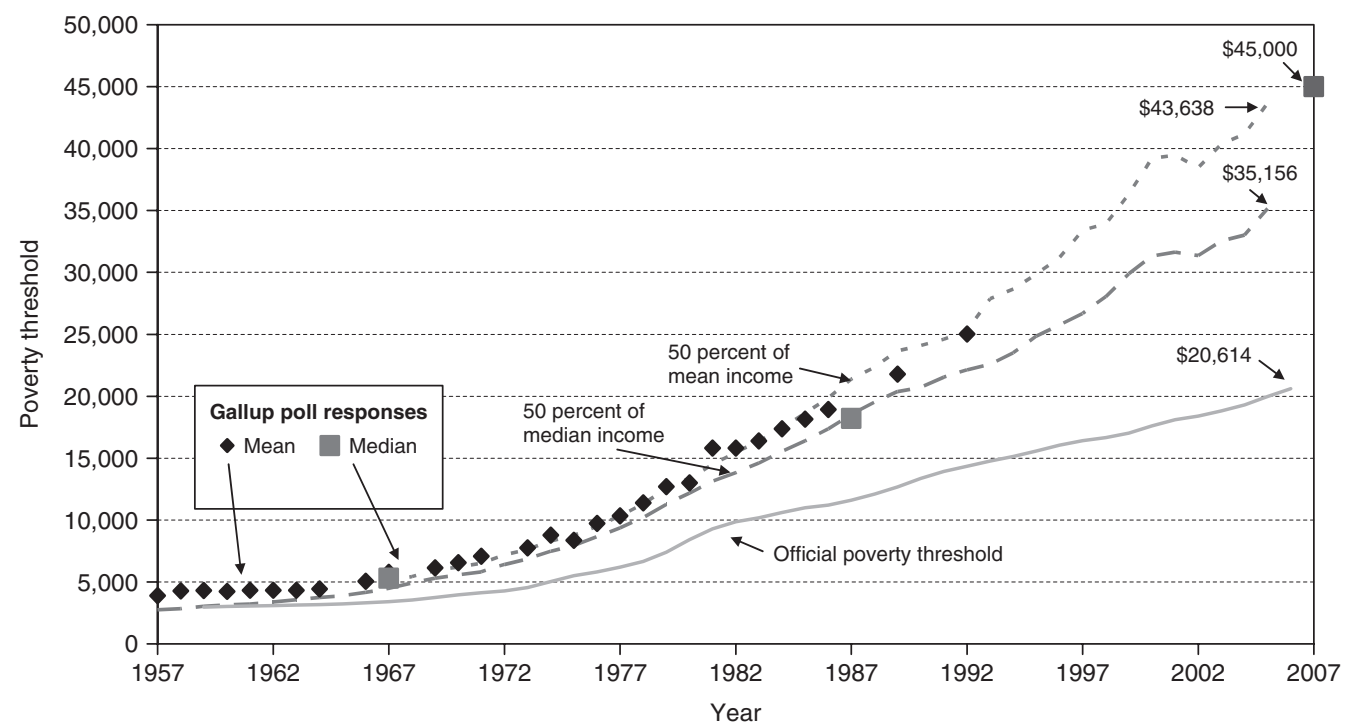

Source: Gallup data from Jones (2007) and Vaughan (1993). Poverty thresholds, median and mean income levels from sources cited in Figure 1.

Note: Gallup polls ask about the minimum amount of money a family of four would need to "get along in your local community." Gallup estimates are response means, except for 1967, 1987, and 2007, which are medians. Mean and median Gallup responses track together closely across the years for which both numbers are available. Fifty percent mean and median income figures and poverty thresholds are for a family of four.

Figure 4. Alternate poverty measures in current dollars, 1947-2007 (for a family of four).

administration for such changes. Strong support from within the research community for these changes also will be necessary.

1. Assign a statistical agency the authority to develop an alternative measure of income poverty, based on the work already done to develop alternative poverty measures. An important part of the assignment is the authority for this measure to be regularly improved and updated.

We must remove control over poverty measurement from within the Executive Office of the President if we want to produce a regularly updated and improved poverty measure. Poverty measurement should be treated like all other statistics. Note that nothing in this recommendation overturns the OMB directive asking that Census continue to compute and report the current official poverty counts. Given this directive requires Census to call this line the poverty rate, it might be very helpful to call the new measure something else. My own recommendation is to call it the Revised Poverty Measure.

It is important that the agency be directed to produce one primary Revised Poverty Measure, although of course ongoing reports in appendix tables on alternative definitions are always useful. It is not useful, however, to produce four or five alternative Revised Poverty Measures and expect people to figure out which is the best one to use. The agency should be given a reasonable timeline, by which point it should be annually reporting the Revised Poverty Measure as part of its official responsibilities.

The agency that has been most involved with developing alternative poverty measures is, of course, the Census Bureau. They have developed poverty and income measures from a variety of surveys and have been involved in all improvement efforts involving poverty measurement. They have, however, limited experience in producing household statistics (like the CPI at the Bureau of Labor Statistics [BLS] 
or Personal Income at the Bureau of Economic Analysis [BEA]) beyond tabulations from their substantial data collection efforts. It is key that the Revised Poverty Measure be handled as similar statistics are handled in other agencies; namely, by the statistical experts and independent from inappropriate department-level interventions. This statistical independence should be emphasized in any legislative directive that delegates this activity to the Census Bureau.

2. Explicitly direct the statistical agency to provide a poverty definition that produces both a credible and coherent poverty threshold and a consistent and appropriate resource measure. Too many poverty measurement alternatives have changed only the resource definition side of the equation. The NAS panel was quite clear that both the resource definition and the thresholds were out of date, and that a consistent definition of both is necessary for an improved poverty measure.

Substantially altering how we count resources without providing a consistent measure of thresholds will only create long-term incoherence in any new poverty statistic. In my opinion, the 1963 poverty thresholds are less defensible than the 1963 definition of economic resources as "cash income only." The thresholds should use the latest available data to calculate a reasonable cutoff level based on a measure that is consistent with the definition used to define resources. For my tastes, I remain quite happy with the NAS recommendations, as implemented by the Census, but I realize that others can disagree with this.

3. Allow public programs to continue to use the OMB-defined poverty rate or multiples of the poverty guidelines as an eligibility cutoff, unless they choose to make changes. Having a different name for the Revised Poverty Measure will make it clear that the eligibility standards written into law need not be changed.

The current poverty rate calculations (and the underlying current poverty thresholds) will have to be calculated by Census on an ongoing basis, because they are directed to do so by OMB. This is necessary because many programs use these numbers. Over time, when programs are up for reauthorization, a decision can be made about whether there are any advantages to switching to the newer poverty measure. If the new thresholds are higher (or lower), then programs can always use a lower (or higher) percentage of the threshold for a cutoff point to avoid discontinuous changes in eligibility cut points. Similarly, programs that allocate funds based on current poverty rate calculations would also have to decide how (if at all) to make changes. Possible ways to deal with these changes need to be reviewed, with suggestions for ways to make the transition to new measures with minimal program disruption. ${ }^{31}$

4. Conduct Commission work to develop a list of key measures of economic deprivation beyond income poverty. This should include some measures of material deprivation as well as alternative measures of economic need.

To develop an informative, credible, and measurable list of alternative economic deprivation statistics will require background work, including developing the criterion by which such statistics might be selected, reviewing existing and potential economic deprivation statistics, and suggesting a specific list of such statistics to be annually included in a "Report on Economic Deprivation in the United States."32 Congress could ask for such work by the National Academy of Sciences, just as it commissioned work on improving poverty measurement 15 years earlier. If Congress is unwilling to appropriate this money, private foundations with an interest in measuring and understanding economic need in this country could approach the NAS and ask for such a report.

My own sense is that there are at least six areas of material deprivation that should be looked at closely to see whether there are measures that might be regularly calculated

\footnotetext{
${ }^{31}$ It may be helpful for the statistical agency to produce a recommended "short-cut procedure" for programs to use in estimating family income (relative to the poverty line) based on a very limited set of questions.

${ }^{32}$ This is exactly the work done by the E.U. committee and reported on in Atkinson et al. (2002).
} 
to quantify the level of problems and progress over time. These six areas include a measure of access to health insurance, some measure of actual health status, a measure of food adequacy or hunger, a measure of literacy or educational preparation, a measure of labor market access, and a measure of neighborhood or housing conditions. If possible in the available data, one might also want to include a measure of aggregate consumption. In some cases, we may have adequate measures already available; in other cases, there may need to be development work to produce such measures.

We should look at several measures of economic need that would provide different information from the Revised Poverty Measure. I would suggest considering at least four measures: estimates of pretax and pre-transfer poverty rates to show the gains from public programs; relative poverty rates or some other measure of income distribution rather than economic need; a measure of "persistent poverty" based on more than one year of income information; and a measure of poverty depth, such as a poverty gap measure that indicates how far the average poor individual is below the poverty line.

Ideally, one would like a set of measures that could be computed from a single data set. Indeed, I would prefer a more limited and rude set of measures from a single data set than a set of more refined measures from multiple data sets. This is because one wants to cross-tabulate these numbers and report how many people are disadvantaged across multiple measures. Or one might also want to tabulate the data based on one key measure, looking at something like health status or health insurance coverage among those who are poor based on the Revised Poverty Measure.

Ideally, a set of such statistics would be regularly reported, along with the Revised Poverty Measure. This would provide us with a more complex and more complete sense of the current problems of economic deprivation, as well as data that show what sort of progress we are making over time on these problems.

The question of whether changes in poverty measurement will increase or decrease the poverty rates should not be a primary focus of this analysis, although this is sure to be a much-discussed aspect of any proposed change. In fact, the actual level of the poverty rate matters less than the extent to which changes in poverty rates are sensitive to appropriate economic and policy changes. That is, we want to measure progress (or regression) over time and this may be more important than the precise level of poverty at any point in time. It may be politically useful to benchmark the aggregate level of the new statistic to the current poverty rate (of course, there may be distribution differences in who is counted as poor within this aggregate number). Such an approach will disappoint those who think current poverty rates are too high and dismay those who think current poverty rates are too low; but because any given poverty level is somewhat arbitrary, benchmarking the new statistic to the current poverty level is an attractive compromise that minimizes the disruption of introducing a new statistic.

I have spent some amount of my time over the past two decades working to change the official poverty measure. This paper argues that working to change the current $\mathrm{OMB}$ directive is not the appropriate place to expend effort. The current poverty measures are what they are, embedded inside a necessarily political agency that has many reasons to avoid change. We need to escape the argumentative box we have been in for several decades and assign responsibility for calculating a Revised Poverty Measure to an agency prepared to take on such a task. At the same time, we need to recognize the inherent limitations in any measure of income poverty. We should catch up with our European cousins and, like them, work to develop multiple measures of economic deprivation.

REBECCA M. BLANK is the Henry Carter Adams Professor of Public Policy at the University of Michigan, and the Robert V. Kerr Visiting Scholar at the Brookings Institution. 


\section{ACKNOWLEDGMENTS}

This paper was prepared as the Presidential Address to the Association for Public Policy Analysis and Management at their annual conference, November 8-10, 2007. Thanks are due to Victoria Finkle for excellent research assistance. The following individuals provided comments or useful conversations but bear no responsibility for the analysis in this paper: Richard Bavier, Doug Besharov, Paul Bugg, Gary Burtless, Connie Citro, Sheldon Danziger, Indivar Dutta-Gupta, Mark Greenberg, David Johnson, Bruce Meyer, Patricia Ruggles, Kathleen Short, Timothy Smeeding, Katherine Wallman, and Daniel Weinberg.

I was a Senior Staff Economist at the Council of Economic Advisers (CEA) in 1990 and led an interagency discussion on the value of making improvements to the poverty line as part of the Improving Economic Statistics initiative; I served on the National Academy of Science's Panel on Poverty and Family Assistance and signed the resulting set of NAS recommendations; I was a member of the CEA in 1997-1999 when poverty measurement changes were discussed within the Clinton Administration; I attended many of the discussions of the seminar "Reconsidering the Federal Poverty Measure," organized by Doug Besharov at AEI in 2003-2004. Although these experiences indicate my credentials as author of this paper, they also suggest I am not an entirely dispassionate and uninvolved observer of these issues.

\section{REFERENCES}

Atkinson, A. B., Cantilon, B., Marlier, E., \& Nolan, B. (2005). Taking forward the EU Social Inclusion Process Report. An independent report commissioned by the Luxembourg Presidence of the Council of the European Union. Report and Annexes. Available at http://www. ceps.lu/eu2005_lu/report/final_annexes.pdf.

Atkinson, T., Cantillon, B., Marlier, E., \& Nolan, B. (2002). Social indicators; The EU and social inclusion. Oxford: Oxford University Press.

Bavier, R. (1999). Three false steps. U.S. Census Bureau, Poverty Measurement Working Paper series. Available at http://www.census.gov/hhes/www/povmeas/papers/falstp.html.

Bernstein, J., Brocht, C., \& Spade-Aguilar, M. (2000). How much is enough? Basic family budgets for working families. Washington, DC: Economic Policy Institute.

Bernstein, J., \& Sherman, A. (2006). Poor measurement: New Census report on measuring poverty raises concerns. Washington, DC: Center on Budget and Policy Priorities.

Betson, D. (1996). Is everything relative? The role of equivalence scales in poverty measurement. U.S. Census Bureau, Poverty Measurement Working Paper Series. Available at http://aspe.os.dhhs.gov/poverty/papers/escale.pdf.

Citro, C. F., \& Michael, R. T. (1995). Measuring poverty: A new approach. Washington, DC: National Academy Press.

Department for Work and Pensions. (2007). Opportunity for all: Indicators update 2007. United Kingdom. Available at http://www.dwp.gov.uk/ofa/reports/2007/opportunityforall2007.pdf.

European Commission. (2006). Portfolio of overarching indicators and streamlined social inclusion, pensions, and health portfolios. Brussels: European Commission. Available at http://ec.europa.eu/employment_social/social_inclusion/docs/2006/indicators_en.pdf.

Fisher, G. M. (1997) (revised). The development of the Orshansky poverty thresholds and their subsequent history as the official U.S. poverty measure. U.S. Census Bureau, Poverty Measurement Working Paper series. Available at http://www.census.gov/hhes/www/povmeas/ papers/orshansky.html.

Gabe, T. (2007). Federal programs that use the "official" poverty definition for determining eligibility or for allocating funds. Memo to the House Ways and Means Subcommittee on Income Security and Family Support. October 30.

Hagenaars, A. J. M. (1986). The perception of poverty. Amsterdam: North-Holland.

Haveman, R. (2007). What does it mean to be "poor" in a rich society?" Draft manuscript. Lafollette School, University of Wisconsin. 
Iceland, J. (2005). Measuring poverty: Theoretical and empirical considerations. Measurement, 3, 208-243.

Jencks, C., Mayer, S., \& Swingle, J. (2004). Who has benefited from economic growth in the United States since 1969? The case of children. In E. Wolff (Ed.), What has happened to the quality of life in the advanced industrialized nations? (pp. 48-80). Northhampton, MA: Edward Elgar Publishing.

Jones, J. M. (2007). Public: Family of four needs to earn average of $\$ 52,000$ to get by. Gallup News Service. February 9. Available at http://www.gallup.com/poll/26467/Public-FamilyFour-Needs-Earn-Average-52000-Get.aspx.

Meyer, B. D., \& Sullivan, J. X. (2003). Measuring the well-being of the poor using income and consumption. Journal of Human Resources, 38, 1180-1220.

Nolan, B., Munzi, T., \& Smeeding, T. (2005). Two tales of Irish poverty. Box 3 in Note on Statistics, Human Development Report (p. 334). New York: United Nations Human Development Office.

Notten, G., \& de Neubourg, C. (2007). Relative or absolute poverty in the US and the EU? The battle of the rates. Maastricht Graduate School of Governance, Working Paper WP001. Available at http://www.bwl.uni-kiel.de/phd/files/paper_notten.pdf.

Rector, R. E., Johnson, K. A., \& Youssef, S. E. (1999). The extent of material hardship and poverty in the United States. Review of Social Economy, 57, 351-387.

Renwick, T. J., \& Bergmann, B. R. (1993). A budget-based definition of poverty, with an application to single-parent families. Journal of Human Resources 28, 1-24.

Ruggles, P. (1990). Drawing the line: Alternative poverty measures and their implications for public policy. Washington, DC: Urban Institute Press.

Sen, A. (1992). Inequality reexamined. Oxford: Clarendon Press.

Smeeding, T. M. (1982). Alternative methods for valuing selected in-kind transfer benefits and measuring their effect on poverty. Technical Paper 50. Washington, DC: U.S. Department of Commerce, Census Bureau. Available at http://www.census.gov/hhes/www/poverty/ prevcps/tp-50.pdf.

Smeeding, T. M. (2006). Poor people in rich nations: The United States in comparative perspective. Journal of Economic Perspectives, 20, 69-90.

U.S. Department of Commerce. (1990). Measuring the effect of benefits and taxes on income and poverty: 1987-88 (Supplemental Data). Series P-60, No. 170-RD. Washington, DC: U S. Department of Commerce, Census Bureau. Available at http://www.census.gov/hhes/www/ poverty/prevcps/p60-170rd.pdf.

U.S. Department of Commerce. (2001). Experimental poverty measures: 1999. Series P60216. Washington, DC: U.S. Department of Commerce, Census Bureau. Available at http://www.census.gov/prod/2001pubs/p60-216.pdf.

U.S. Department of Commerce. (2005). Alternative poverty estimates in the United States: 2003. Series P60-227. Washington, DC: U.S. Department of Commerce, Census Bureau. Available at http://www.census.gov/prod/2005pubs/p60-227.pdf.

U.S. Department of Health, Education, and Welfare. (1976). The measure of poverty: A report to Congress. Washington, DC: U.S. Government Printing Office. Available at http://www.census. gov/hhes/www/povmeas/pdf/measureofpoverty.pdf.

U.S. Department of Labor. (2007). Consumer expenditures in 2005. Bureau of Labor Statistics Report 998. Washington, DC. Available at http://www.bls.gov/cex/csxann05.pdf.

Vaughn, D. R. (1993). Exploring the use of the view of the public to set income poverty thresholds and adjust them over time. Social Security Administration Bulletin, 56(2), 22-46. A slightly updated version of this paper is available at http://www.census.gov/ hhes/www/povmeas/papers/wkppov20_cen.pdf.

Weinberg, D. H. (2006). Measuring poverty in the United States: History and current issues. U.S. Census Bureau, Center for Economic Studies, Working Paper CES 06-11. Washington, DC. Available at www.ces.census.gov/index.php/ces/cespapers?down_key=101751. 